\title{
Hepatectomia por linfangioma em situs inversus totalis - relato de caso
}

\section{Hepatectomy of lymphangioma in situs inversus totalis - case report}

Antônio Wellington lima Soares Júnior, ACBC-PI; Carlos Eduardo Feitosa Tajra, AsCBC-PI; Vitor Yamashiro Rocha Soares²; Jefferson Lemos Soares ${ }^{3}$; Jerri AleXandre Costa ${ }^{4}$

\section{INTRODUÇÃO}

$\mathrm{O}$ Situs Inversus é uma malformação congênita associada com transposição das vísceras. Essa anormalidade pode ser parcial, na qual apenas algumas estruturas estão parcialmente invertidas ou em uma posição anormal, ou total, condição na qual o arranjo normal das vísceras está totalmente invertido, formando uma imagem em espelho da posição normal 1, 2,3,4. A patogênese é explicada por um raro defeito num gene autossômico recessivo herdado de uma penetração incompleta do mesmo 1,5. Este relato mostra uma hepatectomia em paciente com linfangioma hepático associado ao Situs Inversus Totalis.

\section{RELATO DO CASO}

Mulher, 59 anos, casada, parda, analfabeta, foi admitida na instituição apresentando episódios cada vez mais frequentes de dor no Hipocôndrio Esquerdo que havia iniciado alguns meses atrás. Ao exame físico, observou-se o "ictus cordis" no quinto espaço intercostal direito e uma massa palpável na região epigástrica. Aos exames laboratoriais, a Alanina Amino Transferase se encontrava no valor de $68 \mathrm{Uk} / \mathrm{mL}$, a Aspartato Amino Transferase em $50 \mathrm{Uk}, / \mathrm{mL}$ e a alfa-Fetoproteína e a Fosfatase Alcalina, em valores normais. O Raio- $X$ de tórax evidenciou dextrocardia com o arco aórtico voltado para o lado direito (Figura 1). A Ultrassonografia (US) e a Tomografia Computadorizada (TC) revelaram Situs Inversus Totalis, a presença de uma massa sólida $(9,5 \times 7,5 \mathrm{~cm})$, captante de contraste, com densidade de partes moles, de contornos irregulares, localizada em segmentos laterais do lobo esquerdo hepático, sugerindo um hepatoma; além de colecistopatia calculosa (Figura 2). A critério diagnóstico, fez-se uma biópsia guiada por TC e um exame histopatológico, que afastaram a possibilidade de malignidade, tendo como resultado um linfangioma. O quadro clínico da paciente associado ao tamanho do tumor justificou a necessidade da hepatectomia. A cirurgia foi realizada sem nenhuma intercorrência, bem como o seu período

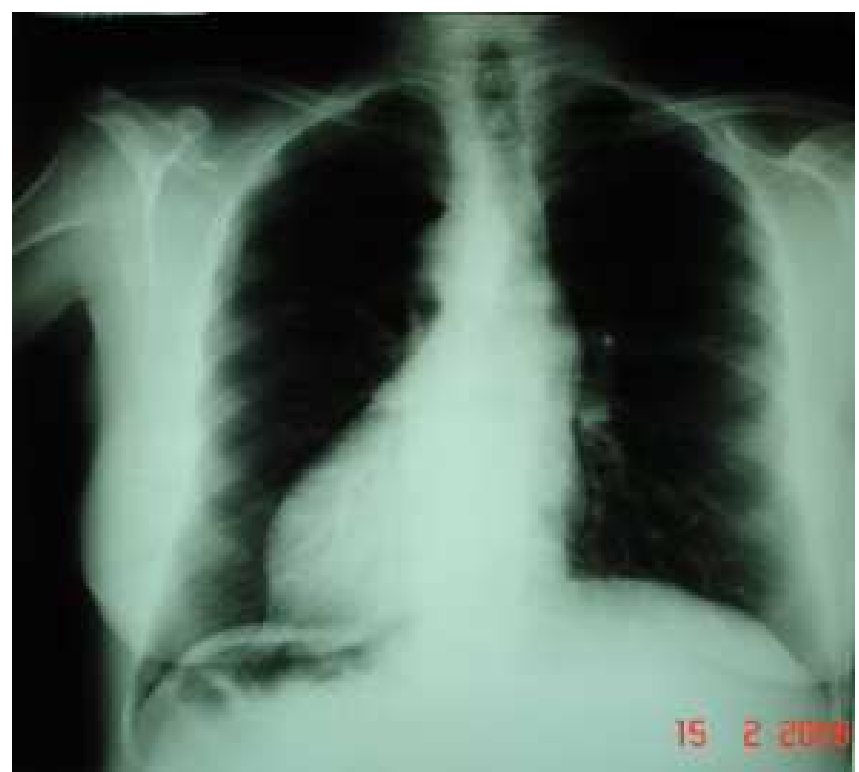

Figura 1 - Raio-X evidenciando dextrocardia.

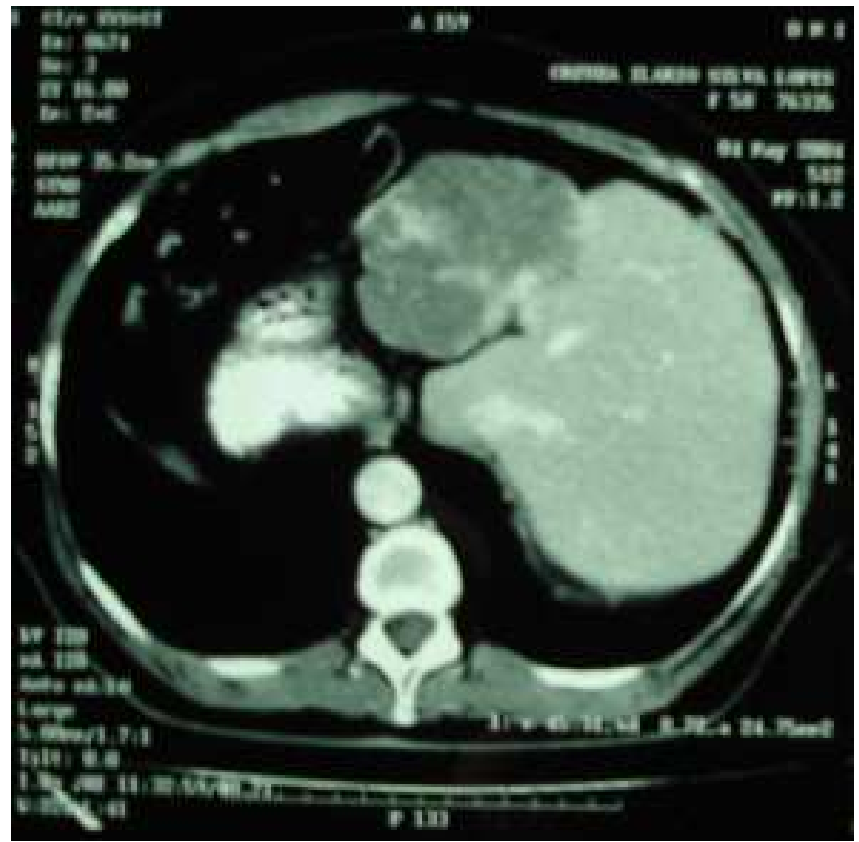

Figura 2 - TC revelando SIT.

Trabalho realizado Serviço de Cirurgia Geral do Hospital Santa Maria. Teresina - Piauí- PI-BR.

1. Cirurgião do Hospital Santa Maria, Teresina - Piauí -PI-BR; 2. Médico do Hospital Santa Maria, Teresina - Piauí - PI-BR; 3. Preceptor do Serviço de Cirurgia Geral do Hospital Santa Maria- PI-BR; 4. Preceptor do Serviço de Cirurgia Geral do Hospital Santa Maria- PI-BR. 
de internação, recebendo alta uma semana após o procedimento. Passado um mês, fez-se uma nova avaliação da paciente, esta se encontrava em um quadro geral bom, anictérica, eupnéica e com ferida operatória em bom aspecto.

\section{DISCUSSÃO}

O Situs Inversus foi primeiramente descrito por Aristóteles em animais e por Fabricius em humanos. A incidência desta heterotaxia é de aproximadamente 1 para $10000^{1,2,3}$, com igual ocorrência em homens e mulheres ${ }^{1}$ 2,3. Na maioria dos casos, os pacientes são assintomáticos e têm uma expectativa de vida normal ${ }^{1,2,3}$. A exata etiologia continua desconhecida, entretanto, o que ocorre é uma má rotação das estruturas embrionárias durante o período fetal. Não há evidências de que o Situs Inversus aumenta o risco de malignização, então, a associação de câncer com essa anomalia congênita é rara, tendo-se somente 4 casos na Literatura, o primeiro descrito por Allen et al em $1936^{1}$ 2,3 . Nosso paciente é o primeiro caso relatado de linfangioma em Situs Inversus Totalis.

Esta condição geralmente não é diagnosticada, a exemplo deste caso, a menos que seja diagnosticada acidentalmente enquanto se investiga alguma doença. Aparentemente, essa variação não influência na expectativa de vida 1,2,3. Entretanto, o Situs Inversus pode estar associado com várias doenças, como úlcera péptica perfurada, abscesso hepático amebiano, colecistite aguda, colelitíase e obstrução intestinal ${ }^{1,3}$. Neste relato, descrevemos uma lesão hepática e colelitíase.

A hepatectomia se torna mais difícil quando realizada em pacientes com Situs Inversus Totalis, em vista disso, o procedimento deve ser realizado por uma equipe experiente.

\section{A $B$ S S T R A A C T}

We present a case of hepatectomy in a patient with liver's lymphangioma associated with Situs Inversus Totalis. The first case of medical literature.

Key words: Hepatectomy, Situs Inversus, Lymphangioma.

\section{REFERENNCIAS}

1. Shiraiwa K, Watanabe A, Sato N, et al. Case Report on Situs Inversus Totalis in Two Sprague-Dawley Rats. Exp. Anim. 1995;44(4):341-45.

2. Niki $Y$, Shiraki K, Enokimura N, et al. Hepatocelular Carcinoma Associated With Situs Inversus Totalis. J Clin Gastroenterol. 2004;38(4):382-3.

3. Pathak KA, Khanna R, Khanna N. Situs Inversus with Cholelithiasis. J Postgrad Med. 1995;41(2):45-46.

4. Banerjee Jesudason SR, Vyas FL, Jesudason MR, et al. Laparoscopic cholecystectomy in a patient with situs inversus. Indian J Gastroenterol. 2004;23:79-80.

5. Song JY, Rana N, Rotman CA. Laparoscopic appendectomy in a female patient with situs inversus: case report and literature review. JSLS. 2004;8(2):175-7
Recebido em 28/02/2007

Aceito para publicação em 01/04/2007

Conflito de interesse: nenhum

Fonte de financiamento: nenhum

\section{Como citar este artigo:}

Soares Júnior AWL, Tajra VYR, Soares JL, Costa JA. Hepatectomia por linfangioma em situs inversus totalis - relato de caso. Rev Col Bras Cir. [periódico na Internet] 2011; 38(6). Disponível em URL: http:// www.scielo.br/rcbc

\section{Endereço para correspondência:}

Carlos Eduardo Feitosa Tajra

Rua Gov Raimundo Artur de Vasconcelos, 616.

Centro/Sul

64001-450 - Teresina - PI

E-mail: carlostajra@hotmail.com 